\title{
Trento Centre continues forward
}

Last update: 13 March 2017

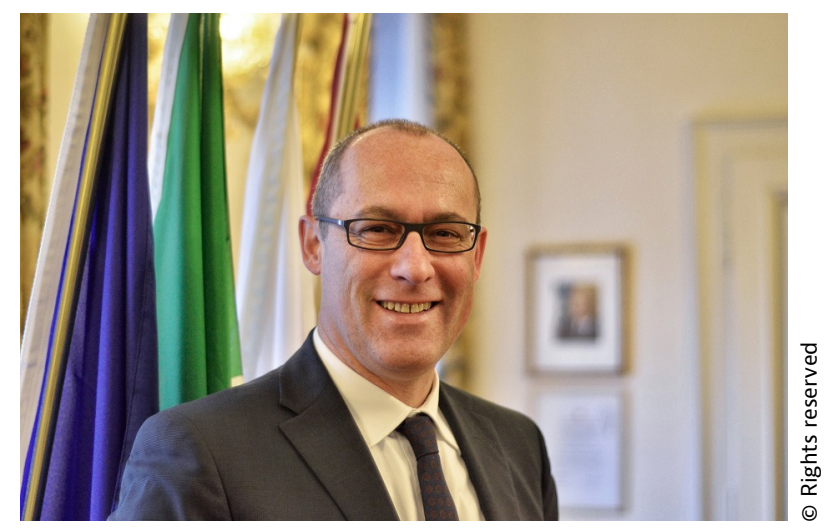

Ugo Rossi

Since 1982 the OECD Programme on Local Economic and Employment Development (LEED) has advised governments and local authorities on how to respond to economic challenges in a fast-changing world. One key initiative in this regard came in 2003 when it set up the Trento Centre for Local Development, with the Italian government and the Autonomous Province of Trento in Italy, with a mission to help build capacity and inform policy actions.

So far the Trento Centre has issued more than 127 reviews, studies, guides and manuals; over 21,000 local development policy makers and practitioners have also benefited from Trento Centre capacity development seminars and activities. In May 2016 the mandate OECD LEED Trento Centre for Local Development was renewed until 2020. We asked the president of the Trento region, Ugo Rossi, to explain.

OECD Observer: Why have you decided to continue your support for the OECD Trento Centre?

President Rossi: By tradition, the Trentino has relied on high-level public administration and advanced policies in the areas covered by the OECD LEED Programme. However, we are determined to improve further and adopt innovative models, in order to build an even more cohesive and stronger region. 
This is only possible through innovation, co-operation and partnerships, and this is exactly what the Trento Centre can help provide. The centre has put down deep roots in our territory, while the partnership has now extended to the whole Triveneto area, spanning Trentino-Alto Adige/Südtirol, Friuli-Venezia Giulia and Veneto. We have also opened a new office in Venice. The dynamic and relatively prosperous Triveneto region is an ideal laboratory for working on issues related to economic and employment development. I am convinced that the enlargement of this partnership, apart from strengthening the Trento Centre in financial and logistical terms, will bring clear benefits for us and the OECD.

\section{How important is the Trento Centre to your region?}

The Trentino, thanks to its special autonomous status within the national territory, has always been very much focused on creating favourable conditions for the development and openness of the region. In recent decades, the Autonomous Province of Trento has made significant investments in the creation of a sophisticated network of institutions, research centres and university departments, with the aim of providing appropriate support to the social, cultural and economic development of the region. The OECD Trento Centre is an important cornerstone in this network, and provides an international perspective to the discussions and initiatives in our territory. It provides a window onto the wider world, which is strategically important for our small mountainous region. Indeed, the Trentino participates in several working groups together with other regions and countries. One example is EUSALP, the European Alpine macro-region that includes 48 Alpine regions, whose mission is to address common challenges in a co-ordinated manner. Another is the EGTC "European Region Tyrol-South Tyrol-Trentino", the European Grouping of Territorial Co-operation (EGTC), which promotes co-operation between the Autonomous Provinces of Trento and Bolzano and the neighbouring territory of Tyrol in Austria, which we share many common characteristics with, including our history.

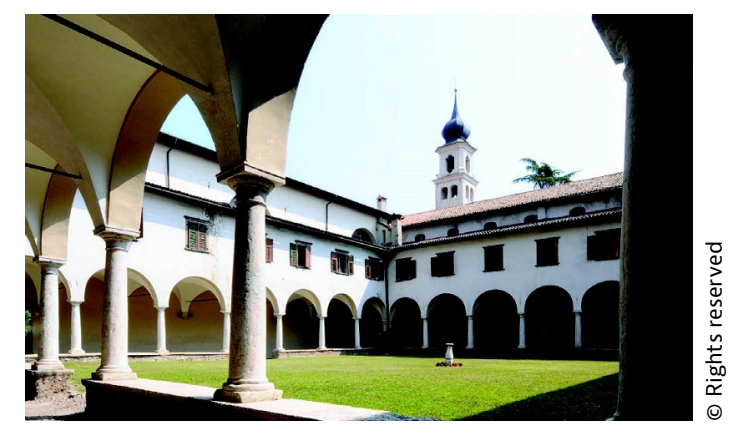

\section{Could the Centre act as a model for others to emulate?}

The OECD Trento Centre for Local Development is a pilot project that could certainly inspire similar initiatives in other countries. Hosting the Centre allows us to have more access and easier dialogue with the OECD, which is an advantage, not least because of the international perspective this offers. And it is an 
advantage for the OECD itself to have daily contact with local territories via the centre, so strengthening its own work.

\section{What would you like to see improve in the next mandate?}

Social cohesion could be one of the topics deserving more attention during this mandate. I believe that social cohesion policies aimed at not leaving anyone behind-the unemployed, elderly, women, young people and immigrants-should characterise all development policies: general and widespread prosperity is a value we cannot do without, if we want to ensure a future of peace and prosperity for our children and grandchildren. Indeed, immigration deserves particular attention by local authorities. The Trentino is committed to addressing the needs of those people who are forced to flee from wars. This implies closely coordinating reception and integration policies, as we must be very careful not to allow the pressures caused by extraordinary migration flows to jeopardise our strong levels of social cohesion.

\section{Twitter@UgoGma}

For more on the OECD LEED Trento Centre, visit www.oecd.org/cfe/leed/ trentocentre.htm

Read the full interview at http://oe.cd/1CD 